\title{
Lecturas de etnografías colaborativas con niñas, niños y jóvenes en contextos educativos latinoamericanos
}

Readings of Collaborative Ethnographies with Children and Young People in Latin American Educational Contexts

Artículo de reflexión | Reflexion article

Fecha de recepción: 20 de octubre de 2020

Fecha de aceptación: 22 de febrero de 2021

Fecha de disponibilidad en línea: junio de 2021

doi: 10.11144/Javeriana.m14.lecn

DiAnA JUdit Milstein diana.milstein4@gmail.com

Centro de Investigaciones Sociales - COniCet Instituto de Desarrollo Económico y Social, Argentina (D) ORCID: https://orcid.org/0000-0002-7849-0973

Alba Lucy Guerrero alba.guerrero@javeriana.edu.co Pontificia Universidad JaVeriana, Colombia ORCID: https://orcid.org/0000-0003-1605-2983

Para citar este artículo | To cite this article Milstein, D. J., \& Guerrero, A. L. (2021). Lecturas de etnografías colaborativas con niñas, niños y jóvenes en contextos educativos latinoamericanos. magis, Revista Internacional de Investigación en Educación, 14, 1-33. doi: 10.11144/Javeriana.m14.lecn 


\title{
Resumen
}

Presentamos un análisis de etnografías colaborativas con la participación de niñas, niños y jóvenes (NNJ). Estos estudios fueron realizados en contextos escolares diversos de Argentina, Ecuador y México, con los cuales nos proponemos mostrar cómo es posible desarrollar etnografías educativas entre adultos y niños sobre fenómenos sociales y culturales de sus vidas cotidianas, sus memorias, sus emociones, y dar cuenta de aprendizajes que trascienden y enriquecen los conocimientos escolares. Metodológicamente, realizamos una lectura analítica sobre cuatro etnografías seleccionadas de un estado del arte previamente desarrollado sobre investigaciones colaborativas con NNJ. Este análisis visibiliza cómo las etnografías realizadas con NNJ aportan al campo de la investigación educativa.

\section{Palabras clave}

Antropología de la educación; investigación participativa; infancia; escuela; América Latina

\author{
Abstract \\ We present an analysis of collaborative ethnographies with \\ the participation of girls, boys and young people (NNJ in \\ Spanish) carried out in different school contexts in Argentina, \\ Ecuador and Mexico. We analyzed how it is possible to \\ develop educational ethnographies between adults and \\ children on social and cultural phenomena of their daily \\ lives, their memories, their emotions and to account for \\ learning that transcends and enriches school knowledge. \\ Methodologically, we carried out an analytical reading on \\ four ethnographies selected from a state of art, previously \\ developed, on collaborative research with girls, boys \\ and young people. This analysis made visible how the \\ ethnographies carried out with NNJ contribute \\ to the field of educational research.
}

\section{Keywords}

Educational anthropology; participatory research; childhood; schools; Latin America 
Descripción del artículo / Article description

El estudio del cual se deriva este artículo de reflexión hace parte de un macroproyecto de investigación de la RIENN presentado al Fondo Fiduciario Pérez-Guerrero para la Cooperación Sur-Sur, en una convocatoria organizada por el Grupo de los 77 de la ONU en abril de 2015. La coordinadora general del proyecto es Diana J. Milstein, integrante del Centro de Investigaciones Sociales (CIS), del Instituto de Desarrollo Económico y Social (IDES) y del Consejo Nacional de Investigaciones Científicas y Técnicas (CONICET) de Argentina. El macroproyecto busca construir estados del arte sobre la investigación colaborativa con niños en cinco países latinoamericanos: Argentina, Brasil, Colombia, Ecuador y México.

\section{Introducción}

En este artículo analizamos investigaciones etnográficas colaborativas realizadas en contextos educativos en países latinoamericanos con la participación de niñas, niños y jóvenes (NNJ), con el objetivo de considerar sus hallazgos respecto a modos de comprender a las escuelas y sus comunidades como contextos de aprendizaje y de actuación política, y de revisar sus aportes en las formas de interrogar, realizar trabajo de campo y escribir resultados en etnografía educativa, desde una perspectiva colaborativa. Los estudios fueron seleccionados de un estado del arte desarrollado en varios países latinoamericanos sobre investigaciones colaborativas con niños y niñas entre 2016 y 2018 en el que, junto a un equipo internacional de colegas, construimos un corpus de investigaciones etnográficas en colaboración con NNJ en Argentina, Brasil, Colombia, Ecuador y México. De ese conjunto de trabajos, seleccionamos cuatro investigaciones, dos de Argentina, una de Ecuador y una de México, cuyos resultados se han publicado en artículos/capítulos y en formato libro/etnografía, con el propósito de indagar cómo son problematizados fenómenos y procesos educativos y sociales, e identificados los hallazgos/descubrimientos sobre los contextos. Estos estudios son particularmente oportunos, porque muestran cómo niñxs ${ }^{1}$ indígenas, campesinos y urbanos, en contextos diferentes, son incorporados como partícipes plenos en proyectos de investigación y logran, junto

1 Haremos uso de la letra $x$ para referirnos a grupos de personas cuya adscripción de género o identificación con un pronombre en particular no se conozca. Se considera que la utilización de la $x$ es una posibilidad de producción de lenguaje no binario. De este modo, con su uso nos distanciamos de aquel lenguaje que remite al mal llamado "genérico" masculino, como del uso del -os/-as, que también colabora con la definición de binarismos. 
a investigadores e investigadoras, comprensiones del contexto desde la escuela y de la escuela desde el contexto. Asimismo, merecieron nuestra atención las particularidades de la modalidad colaborativa de cada estudio para entender cómo varía - conforme los contextos socio-espacio-temporales y los sujetos participantes - la constitución de los equipos/colectivos de investigación, la organización de la participación en cada instancia del proceso de investigación, la vinculación entre investigadores académicos y no académicos entre sí y, por supuesto, los modos de construcción colaborativa de preguntas, datos, descripciones y presentación de resultados. De esta manera, también se posibilita dar cuenta de singularidades epistemológicas y metodológicas de interés para el campo de la etnografía educativa latinoamericana.

El análisis sobre los modos de producción de conocimiento en los contextos escolares y comunitarios, y sobre las modalidades de colaboración en el proceso de investigación, evidencia el aporte de las etnografías con NNJ al campo de la investigación educativa y, junto con ello, a la comprensión de los contextos sociales y culturales en los que se desarrollan dichas etnografías. El término con indica que NNJ se han incorporado a los equipos durante una parte o en todo el proceso de investigación, compartiendo tareas vinculadas a la formulación de preguntas de investigación, al trabajo de campo y/o a la coautoría.

De uno u otro modo, esta modalidad de la práctica etnográfica incluye una expresa e intencionada generación/producción compartida de conocimientos entre investigadorxs académicxs y no académicxs —en este caso, niñxs y jóvenes - y es presentada como parte de los resultados del proceso. Siempre teniendo en vista, que este compartir en ningún caso queda reducido a un rasgo metodológico ni restringe temáticas de investigación a tópicos asociados a la niñez, la infancia y la juventud. Muy por el contrario, conduce a profundizar problemas y comprensiones sobre variadas y amplias temáticas de la vida social. (Milstein, 2020, pp. 4-5)

La producción de conocimiento compartida entre etnógrafos y NNJ, que reconstruimos a través de la lectura de los trabajos seleccionados, exige, en primer lugar, recordar que en etnografía se incorporan los conocimientos locales, poniendo atención y cuidado en la elaboración y producción de saber de las personas que residen y/o trabajan en los lugares seleccionados para realizar los trabajos de campo. Esto supone aceptar que toda la gente tiene disposiciones, aptitudes, capacidades y competencias cognitivas y admitir, al mismo tiempo, que "cada ser humano se encuentra en condiciones muy distintas para producir conocimientos y que existen asimetrías y diferencias en esas condiciones" (Reygadas, 2014, p. 92). 
En segundo lugar, exige explicitar la singularidad de las relaciones entre adultxs y NNJ, así como las maneras en que fueron construidas y las estrategias que se pusieron en marcha para lidiar con distorsiones adultocentradas, privilegiando las percepciones, perspectivas y conocimientos de los NNJ. Privilegiar, en el sentido de dar lugar a que lo que cuentan, actúan y explican acerca de las experiencias vividas tenga, en la investigación, una escucha y un impacto similar al de otros interlocutores. De ahí que, en tercer lugar, es necesario considerar que en las etnografías colaborativas analizadas en este artículo, el conocimiento producido por NNJ ingresa, porque aporta una comprensión singular y necesaria, dada la posición que estos tienen en las relaciones sociales y en los equipos de investigación, y porque en muchas oportunidades desafían la comprensión establecida y naturalizada por los adultos.

A continuación, presentamos una breve caracterización de la etnografía educativa en colaboración con NNJ y una descripción de la modalidad de lectura y análisis reflexivo de las investigaciones seleccionadas para situar epistemológica y metodológicamente este trabajo. Luego, desarrollamos una breve reseña de las cuatro investigaciones seleccionadas; posteriormente, presentamos dos apartados analíticos y de discusión, en los que abordamos la manera como estas investigaciones colaborativas desde la escuela permiten comprender procesos y fenómenos propios de los contextos y de las mismas escuelas y singularidades de las modalidades colaborativas con NNJ. Finalmente, el cierre lo dedicamos a exponer conclusiones y argumentos sobre las posibilidades y virtudes que presenta la etnografía colaborativa con NNJ, como enfoque, para la producción y expansión del conocimiento en educación.

\section{Una lectura reflexiva de la etnografía educativa en colaboración con NNJ}

En el campo de la educación en Latinoamérica, la investigación etnográfica ha tenido desde inicios de los años ochenta una influencia manifiesta de la educación popular y de la investigación participativa (Barabtarco, Zedansky \& Porschner, 1998; Batallan, 1998; Bertely \& Corenstein, 1998; Levinson, Sandoval-Flores \& Bertely-Busquets, 2007; Milstein, Clemente \& Guerrero, 2019; Rockwell, 1998) que alentó, entre otros aspectos, el trabajo colaborativo entre investigadores universitarios y no universitarios, mayoritariamente maestros y profesores de escuelas primarias y secundarias. Esta forma colaborativa de investigación debe ser comprendida en el contexto político y social de resistencia a los regímenes autoritarios/dictatoriales de varios países de la región, en la cual participaban equipos académicos cuyas 
investigaciones se articulaban con proyectos de transformación social, en general, y de la educación escolar y no escolar, en particular (Gajardo, 1985; Rockwell, 1998; Torres \& Cendales, 2006, entre otros). La colaboración entre maestros y profesores e investigadores en estudios etnográficos enriqueció la comprensión de los roles de maestros y estudiantes y de la vida cotidiana de la escuela, y la producción de conocimiento detallado de estas y las comunidades. Además, evidenció posibilidades de articulación entre teoría y práctica, cuestionando el tratamiento de los sujetos sociales como objetos en las investigaciones (Fals-Borda, 1978; Milstein et al., 2019). Probablemente, esto abonó el terreno para que tiempo después, en el contexto jurídico-político, social, cultural y académico, algunas investigaciones etnográficas educativas realizadas en países latinoamericanos incluyeran la participación y colaboración de niñas, niños y jóvenes como sujetos de derecho, agentes activos y reflexivos. Esto implicó investigaciones que consideraran de manera explícita sus aportes en la comprensión y transformación de las dinámicas sociales y educativas, que reconocieran su papel protagónico en las comunidades. Hacia fines de la década de los ochenta, con la aprobación de la Convención de los Derechos del Niño de la Organización de las Naciones Unidas (1989), se desarrollaron investigaciones cualitativas y etnográficas en las que NNJ eran considerados interlocutores válidos. Este rumbo quedó plasmado, entre otros, en la conformación de programas sobre childhood studies (estudios de la infancia) y de children's geographies (geografía de los niños) en países europeos y de América del Norte, además de los estudios sociales y educativos realizados por investigadores latinoamericanos que cuestionaban las nociones de desarrollo y socialización de Ixs niñxs propuestas por la psicología del desarrollo y la sociología de corte funcionalista (Pavez Soto, 2012; Vergara et al., 2015).

La etnografía colaborativa utilizada por las investigaciones que analizamos aquí se sostiene en relaciones coetáneas que estimulan el flujo intersubjetivo y fomentan la coproducción entre investigadores y sujetos que residen, trabajan y/o estudian en el lugar donde se desarrolla el trabajo de campo. En estos estudios, Ixs investigadorxs profesionales constituyeron equipos con niños y niñas, a los que integraron como interlocutores, trabajadores de campo y coautores, en una relación de equidad temporal en la que procuraron percibirse como partícipes de un mismo contexto y de una misma época. Fabian (2007) usa la noción de covalencia para referirse a la relación de colaboración en un tiempo y un espacio compartido, en los que tanto Ixs participantes como Ixs entografxs producen un conocimiento mediado por eventos y prácticas performativas que surgen de los diálogos colaborativos (Milstein et al., 2011). Lxs etnógrafxs están atentxs a no perder de vista que ellxs, como Ixs niñxs, también piensan, 
conocen y comprenden con las lógicas de las emociones, los sentimientos, la racionalidad y el cuerpo, y asumen que esa posición contribuye a generar condiciones para que fluya la intersubjetividad necesaria para motorizar la producción colaborativa de conocimiento (Guerrero et al., 2017). De ahí que el conjunto de estrategias, técnicas, métodos, estilos de participación, modos de llevar adelante el trabajo de campo y de representar los resultados en cada investigación puede ser muy diverso, creativo y original y, en todos los casos, puede constituirse en un aporte innovador para la propia investigación educativa.

\section{Metodología}

Para alcanzar los objetivos propuestos en este artículo revisitamos las publicaciones reunidas en el estado del arte sobre etnografía con NNJ realizadas por miembros de la RIENN en Argentina, Brasil, Colombia, Ecuador y México. De la revisión de este estado del arte, surgieron nuevas cuestiones sobre los estudios etnográficos que involucran a niños y niñas en el proceso de investigación, en escenarios educativos, y que se presentan como una oportunidad para hablar sobre el potencial de la etnografía en contextos educativos. Metodológicamente, esta investigación se estructuró en tres momentos o fases que orientaron las actividades necesarias para lograr los objetivos propuestos:

\section{Primer momento: Selección de los estudios etnográficos}

Del conjunto de publicaciones mencionado, seleccionamos, para este trabajo, estudios en los que la colaboración de NNJ se presenta de manera explícita y abarca la problematización, el trabajo de campo y la elaboración de resultados. También utilizamos como criterio de selección el hecho de que las publicaciones presentaran discusiones focalizadas en contextos educativos rurales y urbanos y se destacaran por su interés en la producción de conocimientos sobre sus territorios, por el uso de estrategias comunicativas diversas que incluyen textos visuales, verbales y musicales, y por considerar a la escuela como un escenario de aprendizaje y de acción política.

\section{Segundo momento. Lectura y descripción de los estudios}

La lectura que realizamos de las cuatro investigaciones seleccionadas presenta una diferencia respecto a formas habituales o convencionales de examinar antecedentes para organizar estados del arte, panoramas sobre temas y tópicos o reseñar investigaciones. Leímos atendiendo al proceso vivencial llevado a cabo para lograr que los cuatro textos completaran una experiencia etnográfica. Nos interesó observar cómo las historias que se 
contaban y las formas de comprenderlas y articularlas con conceptos iban transformando a Ixs actorxs, aunque no siempre esto se narraba al percibir otras sensibilidades que nos conducían a familiarizarnos con creencias y formas de ver la enseñanza y el aprendizaje, extrañarnos de nuestros modos de pensar y sentir, y de entender a los niñxs, a los maestrxs, a los familiares y, también, a lxs propixs etnógrafxs. Aprovechando las posibilidades performativas de estos textos, ensayamos a participar de los recorridos, paseos, eventos, intercambios de textos y escenas reportadas, e incluirnos, dialogando con las conversaciones entre participantes. El descubrimiento de mundos sociales fue sorprendente. Por un lado, implicó la manera en que logramos aproximarnos a gente y lugares que desconocíamos, y por otro, posibilitó el encuentro con investigadorxs académicxs, recreando espacios y tiempos con los niñxs y descubriendo modos de conocer y entender con ellos. Todo esto a través de una lectura enfocada en las investigaciones como experiencias vitales.

Nuestra aspiración fue encontrar estrategias de lectura analítica para dar continuidad a nuestra manera de contar en qué consiste la etnografía en colaboración con niñxs y jóvenes. Internarnos en las historias contadas en los textos que produjeron estxs investigadorxs adultos y niñxs exigió flexibilizar y dejar fluir ideas y nociones, y estar dispuestas a compartir la riqueza de los procesos de creación de sentido. En estas investigaciones, uno de los desafíos consistió en expresar en forma escrita experiencias corporizadas y sentidos encarnados que, en muchos casos, durante el trabajo de campo, parecen organizarse en tensión con el lenguaje verbal. De este modo, Ixs autorxs apelan a textos que incluyen variadas formas de representación como: escritura, fotos e imágenes, dibujos e ilustraciones, buscando modos de expresar/comunicar un conocimiento producido colaborativamente. Como se puede apreciar en lo que sigue, la lectura nos condujo a preguntarnos sobre la conformación de los equipos de investigación, el rol de lxs niñxs en el trabajo de campo y en los modos de representación de estos datos y, particularmente, sobre la escritura y la multiliteracidad (multiliteracy) ${ }^{2}$.

\section{Tercer momento. La escritura}

El análisis nos permitió, desde la perspectiva de los investigadores de los casos seleccionados y desde nuestra propia mirada como etnógrafas, desarrollar una línea argumentativa que expone con mayor profundidad la

2 Se entiende multiliteracidad como la posibilidad de identificar, interpretar, crear y comunicar significados a través de una variedad de formas de comunicación visuales, orales, corporales, musicales y escritas. 
manera en que las investigaciones facilitan la construcción de conocimiento desde la escuela sobre los aspectos culturales y sociales propios de cada territorio, las prácticas colaborativas de investigación de niños y niñas, y la relación de estos procesos con escenarios educativos convertidos en ámbitos de acción política.

\section{Cuatro reseñas entramadas}

Estas cuatro investigaciones fueron seleccionadas porque presentan una propuesta etnográfica común, que consiste en que Ixs niñxs tienen un papel protagónico durante todo el proceso de investigación. También, porque abordan tópicos de interés para la investigación educativa y porque, además, dentro del ámbito escolar ponen en entredicho los roles asignados a Ixs niñxs como aprendices en procesos de socialización y a adultos como enseñantes ya socializados.

La participación de Ixs niñxs fue diferente en los equipos de investigación, en cuanto a la cantidad de participantes, a la forma elegida para orientarlos y entrenarlos como etnógrafos, y a las estrategias colaborativas utilizadas para las distintas etapas del proceso investigativo. Estas diferencias están ligadas a los temas y problemas de investigación y a los contextos empíricos en los que se desarrolló cada una.

Los estudios conducidos por Patricio Guerrero Arias, en una localidad urbano-rural de Ecuador, y por Rossana Podestá Siri, en localidades rurales y urbanas en México, tuvieron desde su inicio la intención y decisión de realizar etnografías colaborativas con niñxs en escuelas primarias. Las etnografías realizadas por Carolina Gandulfo, en una localidad rural de Argentina, y por Diana Milstein, en una urbana del mismo país, no incluyeron en su diseño inicial la colaboración de niñxs, sino que estos fueron integrados a la investigación cuando el trabajo de campo ya se había iniciado, y su colaboración resultó decisiva en el curso que tomaron los estudios.

Memorias vivas fue un proyecto realizado con niños de quinto, sexto y séptimo año de una escuela primaria del barrio Catzuquí de Velasco, situado al noroccidente del Distrito Metropolitano de Quito, Ecuador. El proyecto fue coordinado por Patricio Guerrero y:

[...] pretendió un acercamiento a los múltiples rostros y rastros de las diversidades que habitan las comunidades de Catzuquí de Velasco, y escuchar y hablar "con" y "desde" las propias voces de las y los legítimos sembradores y constructores de cultura, de ancianas y ancianos, de jóvenes, niños y niñas, de mujeres y hombres que hacen desde su diario cosmovivir; que Catzuquí de Velasco sea lo que es. (Guerrero, 2017, p. 17) 
Por su parte, el proyecto conducido por Podestá Siri (2007b) se interesó por las representaciones sociales que tenían Ixs niñxs acerca de sus pueblos y situó su trabajo de campo con comunidades nahuas, con niñxs de quinto y sexto grado de instituciones educativas de tres localidades de México: Magdalena Yancuitlalpan, ubicada en las faldas del volcán Popocatépetl; San Miguel Eloxochitlán, cabecera del municipio más marginado de la Sierra Negra, y en Tehuacán y colonia Loma Bella, en la ciudad de Puebla. Desde la perspectiva de Podestá Siri, con este proyecto intentó:

[...] crear una nueva entrada metodológica basada en la evocación, donde ellos [lxs niñxs] construían sus propios mundos [...]. Al cederles la palabra dos procesos se gestaban paralelamente. El nativo habla de sí y de su grupo; reflexiona sobre su actuar y su ser. El antropólogo observa y conceptualiza este proceso evocado por él mismo, al promover el diálogo que establece con los niños nativos a partir del conocimiento de sus realidades. [...]. De esta manera se construyen dos discursos complementarios (el de los nativos y el del investigador) que dan como resultado dos caras del mismo fenómeno. (Podestá Siri, 2007b, p. 998)

Entiendo pero no hablo fue una investigación realizada por Carolina Gandulfo, que definió a la escuela primaria como lugar central para estudiar los usos del guaraní y el castellano en un paraje rural de la provincia de Corrientes, en Argentina. Durante el curso del trabajo de campo que la investigadora realizaba con la colaboración de una maestra, decidió invitar a participar en la investigación a tres niñas de quinto y sexto grado, con el objetivo de "mirar la realidad lingüística de los niños de la escuela a través de los ojos de otras niñas mayores" (Gandulfo, 2007, p. 51). Con la participación de las niñas, la investigadora pudo conocer las lenguas que hablaban Ixs más pequeñxs y lograr una mejor comprensión de aspectos claves sobre el contexto sociolingüístico y la ideología lingüística, importantes para su estudio sobre "el funcionamiento del discurso de la prohibición del guaraní y las significaciones que tenían los modos en que se podía o no aprender el castellano o el guaraní para los niños" (Gandulfo, 2016, p. 82).

La nación en la escuela fue un estudio sobre las tensiones y disputas políticas que surgen en la vida cotidiana escolar y la diversidad de roles sociales que intervienen en ellas (Milstein, 2009). El trabajo de campo fue realizado en Villa La Florida, una localidad situada al sur del conurbano bonaerense, Argentina. En el proyecto inicial, la investigadora Diana Milstein, coautora de este artículo, había definido a Ixs docentes técnicos, parientes, autoridades y vecinxs como interlocutores privilegiados, pero la escucha atenta a sus intercambios con los niños la estimularon a 
incorporarlos no solo como interlocutores fundamentales, sino también como investigadores.

En el apartado siguiente veremos cómo el proceso de investigación compartido con niñxs en estos estudios generó condiciones inestimables para acceder a las escuelas en contexto y a los contextos en las escuelas, recorriendo y entramando relaciones y vínculos que constituyen tanto a los grupos sociales como a las instituciones. Niñxs, actores con agencia y autonomía, pusieron en escena y en discusión temas como los usos legítimos e ilegítimos de las lenguas, la relación entre el trabajo y la política en los barrios, y los sentidos de la memoria colectiva y el patrimonio, de maneras originales y no previstas por Ixs investigadorxs. Mostraremos también cómo las modalidades colaborativas con niñxs ponen en debate aspectos epistemológicos, metodológicos, éticos y políticos de la investigación educativa.

\section{Dejar fluir el conocimiento local con los niñxs}

En las cuatro etnografías estudiadas, las decisiones tomadas por Ixs investigadorxs respecto a la forma de incoporar a lxs niñxs, las estrategias para construir relaciones con ellxs como equipo y las actividades que despliegan Ixs niñxs, se corresponden con los vínculos que se construyeron durante el trabajo de campo compartido y con los contextos y escuelas en los que se desarrollaron los estudios. Así, la dificultad que experimentaba Gandulfo, en un contexto histórico de prohibición de una lengua originaria, para situar a los niñxos hablantes de guaraní en la escuela, la condujo a pedir ayuda entre Ixs propixs niñxs. ¿Cómo se le ocurrió esta idea? Ella ya estaba en la escuela colaborando como investigadora en la implementación piloto de una propuesta de alfabetización inicial bilingüe y advirtió que la visión adulta del contexto lingüístico resultaba insuficiente. Necesitaba "mirar la realidad lingüística de los niños de la escuela a través de los ojos de otras niñas mayores" (Gandulfo, 2007, p. 51). Acudió a tres niñas, con las cuales logró censar lingüísticamente la población de estudiantes de primero y segundo grado de la escuela, con quienes la investigadora había tenido previos acercamientos poco exitosos. Esto demostró, que las niñas se conectaron con la pregunta empírica de investigación de la etnógrafa, que tenían competencias lingüísticas en guaraní y que contaban con un conocimiento local circulante entre los integrantes de los grupos familiares. En palabras de la investigadora:

La manera en que ellas encararon la consulta nos mostró las competencias lingüísticas en guaraní que estas niñas tenían porque para poder evaluar su competencia lingüística les hablaban en guaraní a los niños 
más pequeños. Asimismo conocían a familias de los niños y podían inferir cierto conocimiento de la lengua respecto a identificar a sus familias como hablantes de guaraní o no. Establecieron categorías de aprendizaje del castellano al identificar que los niños hablaban "bien", "más o menos" o "mal", lo cual nos dio la pauta de la graduación valorativa de un aprendizaje, considerando el castellano como una segunda lengua que se aprendería en la escuela. Respecto al guaraní, las categorías señalaban si los niños eran hablantes identificándolos con un "sí" o "no", lo que daba cuenta de la consideración del guaraní como lengua materna, o lengua de adquisición familiar o comunitaria. (Gandulfo, 2016, p. 83)

Por su parte, Podestá Siri también consideró relevante para su estudio, vinculado a tradiciones lingüísticas, alentar una comunicación entre pares. Para ello, promovió un diálogo interindígena entre niñxs nahuas de los pueblos y de la ciudad a través del envío de cartas. Invitó a grupos de clases completas en las escuelas, abriendo la posibilidad de participar o no en la experiencia. La investigadora propuso que contaran a un niñx de otra escuela y otro pueblo cómo era su pueblo y cómo era cada unx. Ella Ixs consideraba a todxs expertxs en la cultura en la cual se habían socializado y por eso asumió que sabrían qué contenidos destacarían de su propia lengua, de su cultura y de sí mismxs. Quedó sorprendida porque todxs participaron y las maestras cedieron su lugar en la clase, para que la investigadora orientara la experiencia. La clase en la escuela se convirtió en un lugar privilegiado para entender que, como grupos nahuas, eran depositarios de tradiciones lingüísticas y culturales comunes, que ponían de relieve una conciencia étnica y lingüística forjada en experiencias propias y familiares, y que la memoria colectiva se fundía con el entorno.

Siempre les recordaba que sin su participación libre y decidida no podíamos llevar a cabo el proyecto, porque ellos eran los autores, el motor. Iban a contar cómo era su pueblo a los niños de otro pueblo nahua y de la ciudad. Nadie mejor que ellos para hablar del lugar que los vio nacer. En ese sentido, desde el principio intenté que entendieran que yo no podía realizar el trabajo con sus ojos, oídos y sentimientos; que si bien podía hablar de su pueblo, no lo haría igual que si hubiera nacido allí, como lo hace un nativo [...] nadie mejor que ellos sabía qué y cómo decirlo, sobre qué contar, les decía que yo no había nacido allí, que ignoraba qué era lo que ellos querían decir sobre su pueblo, que esa decisión era propia. Tenían la libertad de decir y organizar lo producido con base en su criterio. (Podestá Siri, 2007a, pp. 35-36)

Por su parte, Guerrero Arias comenzó por conversar con miembros del Consejo de Gobierno del pueblo Kitu Kara, con quienes compartía la 
preocupación por el impacto que las tecnologías de la información estaban teniendo sobre jóvenes y niñxs de sus comunidades, y de allí surgió la idea de trabajar sobre procesos de revitalización de las culturas, las identidades y las memorias de la comunidad de Catzuquí de Velasco (Guerrero Arias, 2017). Fue ese el punto de partida que lo condujo a "hacer un levantamiento etnográfico que permitiera que las mismas niñas y niños fueran los ejecutores del trabajo, con la finalidad de que conozcan por sí mismas/os su realidad sociocultural" (Guerrero Arias, 2017, p. 23). La decisión de involucrar niñxs tenía una importancia no solo teórica y metodológica, sino fundamentalmente política: asumir que a través de la investigación Ixs niñxs podían sentir y pensar, "para que desde una sensibilidad reflexiva y una reflexibilidad sensitiva, miren que la cultura, la identidad y la memoria están vivas, que no están muertas" (p. 16). El proyecto incluía que las distintas áreas de conocimiento que se enseñan en la escuela se enriquecieran con los aportes que produciría la investigación sobre geografía, historia, ciencias naturales y lengua. Así decidió invitar a participar como etnógrafxs a todxs Ixs niñxs de los cursos de sexto, séptimo y octavo año de una escuela primaria, así como también a sus maestrxs. El proyecto comenzó con la puesta en marcha de talleres interactivos en los que se organizó el equipo con Ixs niñxs, se construyeron las preguntas y se planeó el trabajo de campo. La propuesta era, desde el inicio, mostrar que "la investigación no es un acto solo de expertos, algo difícil y complicado, sino por el contrario queríamos que sientan que también la investigación puede ser como un juego y que nos podemos divertir al investigar" (Guerrero Arias, 2017, p. 23). El investigador logró comprender que el sentido de las cosmovisiones, las identidades y la memoria también se experimentan en el jugar como modo de investigar. Esto le permitió reconstruir una noción que también sirve como fundamento para la revitalización de la cultura indígena, a la que nombra corazonar, como un modo de sentipensar la realidad.

Para el mundo occidental capitalista, nuestra humanidad depende solo de la razón, por eso se piensa que somos solo seres racionales; para la sabiduría Secoya: Somos estrellas con corazón y con conciencia, es decir que nuestra humanidad depende de la fuerza del corazón y la razón, por eso las sabidurías indígenas, son sabidurías del corazón. (Guerrero Arias, 2017, p. 150)

Diana Milstein fue a una escuela primaria, situada en un barrio popular, con el interés de comprender cómo las formas de organización y participación social y política que se desenvuelven fuera de la escuela actuaban e intervenían en la cotidianeidad escolar. Este era un tema que, en 
principio, no parecía involucrar el protagonismo de los niñxs de la escuela. En un diálogo casual con una niña de quinto grado, ella contó cómo con sus compañeros de clase habían logrado que echaran a una maestra que los maltrataba. Las dificultades concretas para recorrer el barrio y hablar con los vecinos le ponían freno a la investigación de Diana, pero permitieron que la investigadora advirtiera que Ixs niñxs eran excelentes interlocutorxs para su investigación. Así, propuso a la directora y a las maestras realizar de manera experimental un trabajo etnográfico con niñxs de la escuela. La propuesta fue aceptada y la investigadora convocó a niñxs de quinto, sexto y séptimo grado. Un grupo quedó constituido por siete niñxs con quienes trabajó durante tres meses del primer año, y el otro fue un grupo de seis niñxs que colaboraron durante el año siguiente. Con ambos grupos realizó un trabajo de campo, que incluyó la documentación sobre la vida cotidiana, la producción de datos y su análisis, y la escritura de textos que fueron publicados de manera artesanal por la escuela. Los períodos de investigación colaborativa fueron claves para:

[...] ver como políticos fenómenos de la escuela que ni la literatura académica ni el sentido común (adulto) los etiquetarían como tales [...] La política se hizo evidente donde se suponía que faltaba, en el aula, y lxs niñxs aparecieron con experiencia en las prácticas sociales de las cuales se suponía que no sabían casi nada. (Milstein, 2010, p. 143)

Así como fue posible dar visibilidad a procesos políticos en la cotidianidad escolar, los cuatro estudios presentan de diferentes maneras otras facetas de la vida en las escuelas, que habitualmente quedan invisiblizadas por los modos de comprensión aceptados y naturalizados de sentido común. Aquí hacemos principalmente referencia al:

[...] sentido común pedagógico que no es conocimiento vulgar, opuesto al discurso ilustrado de los pedagogos y didactistas. Es una construcción compleja y heterogénea que articula fragmentos de discursos filosóficos, teorías científicas, creencias religiosas, conocimientos empíricos, saberes prácticos, etc. [...] cuyos fundamentos y razones, por su mismo pasaje al sentido común, quedan luego velados y, en gran parte, desconocidos como tales y sus significados pasan a ser parte de lo obvio e integran definiciones compartidas de lo que "es" la escuela. (Milstein \& Mendes, 2017, p. 89)

El equipo en Ecuador visibilizó la memoria y el patrimonio desde la perspectiva de las memorias vivas (dejar fluir el saber local), diferenciándose de los modos vigentes en los currículos escolares que tienden a priorizar 
objetos, cosas, muebles, y a silenciar las voces de los seres humanos, invisibilizando con ello el potencial transformador que tiene el patrimonio como herencia social transmitida por los ancestros (Guerrero Arias, 2017). La colaboración de las niñas investigadoras de Corrientes fue clave para que la etnógrafa pudiera mostrar al "guaraní como 'otra' lengua presente en la escuela, hablada por los niños" (Gandulfo, 2007, p. 174), y a la vez para hacer visible que, incluso en lugares en que se desarrollan experiencias escolares de enseñanza bilingüe como la escuela, prevalecen estrategias pedagógicodidácticas que no tienen en cuenta la realidad sociolingüística de Ixs niñxs, coincidentes con "el imaginario de una nación construida sobre la base de representaciones y concepciones monolingües: argentino = castellano" (Gandulfo, 2017, p. 174). La experiencia de coautoría con niñxs de tres localidades de México, que retomamos más adelante en su aspecto metodológico, permitió hacer visible el carácter grafocéntrico del sistema escolar, que obstaculiza las posibilidades de apropiación de la escritura por parte de Ixs niñxs, y resalta la necesidad de la apertura a otros lenguajes para expresar aspectos significativos de las culturas.

Otro aporte significativo se vincula a la comprensión que alcanzaron de los territorios donde están las escuelas y residen Ixs niñxs. Esta dimensión aportó resultados importantes en términos educativos con relación a las formas de aprehender espacios y lugares. Podestá Siri, por ejemplo, muestra que las diferencias en los modos de entender las relaciones entre los lugares y los seres que los habitan y entre naturaleza y trabajo humano están estrechamente vinculadas al lugar donde residimos: pueblo o ciudad. Quienes viven en los pueblos logran:

[...] rastrear una memoria no escolarizada sobre su territorio, heredada de abuelos a padres y de padres a hijos que los remonta al origen de los hombres y de las cosas que están sobre la tierra [...] un pensamiento analógico donde la naturaleza son los mismos hombres [...] Una relación directa entre los lugares y los seres que los habitan. (Podestá Siri, 2007a, p. 171)

Y entre quienes habitan la ciudad:

[...] hay una disociación entre su mundo real, el que habitan, y el mundo que narran aprendido de sus abuelos y padres, es decir, las creencias adquiridas en los pueblos de origen [...] los nuevos espacios no se pueden llevar la tierra, pero sí las narrativas y creencias que los niños manejan a pesar de vivir en la ciudad. (Podestá Siri, 2007a, p. 171)

Por su parte, Guerrero Arias orientó a los niños y niñas a caminar por "donde la comunidad teje la vida" (Guerrero Arias, 2017, p. 26), mirando, 
participando, conversando, escribiendo y dibujando sobre los lugares, los animales y los vegetales, siempre en relación con lo que cuenta y hace la gente. También, los invitó a dibujar mapas en los que integraban la riqueza natural, biológica, paisajística y turística de la comunidad, ubicando las casas, la escuela, la cancha de fútbol, la iglesia, las montañas, las lomas, los ríos, las fuentes de agua, los animalitos, las tiendas, la parada del bus, los caminos, etc. Este ejercicio reveló la importancia del mapa para delimitar qué es centro y qué es periferia, o quiénes están arriba y quiénes abajo en ese territorio que habitan, y así conectar la espacialidad con la construcción de identidades y memorias.

También Milstein resalta "cómo se han ido relacionando entre sí 'indicadores de recorridos e indicadores de mapas' (De Certeau, 2007, p. 131) durante los encuentros etnográficos con los niños y las niñas" (Milstein et al., 2011, p. 236). Esto condujo a que utilizara categorías como adentro/ afuera, para representar fronteras entre grupos sociales. La expresión los de adentro fue utilizada para indicar el área donde residían las familias mejor acomodadas económicamente, como una marca social indicadora de quienes se concebían como "los otros" en relación a las demás áreas de la localidad: el centro, donde residían los integrantes del equipo de investigación y estaba situada su escuela; la zona comercial; el área de otras escuelas, donde vivían familias como las del centro; y lo que le dicen la villa, el área más precaria de la localidad.

Así, en estas etnografías, la participación de los niños y las niñas ha sido decisiva para reconstruir perspectivas sobre los actores y sus reflexividades. Además, permitió contar con un conjunto dispar, heterogéneo y muchas veces contradictorio de datos que, organizados como conocimiento local, permitieron elaborar marcos teórico-empíricos apropiados a la investigación etnográfica, rica en producción de conocimiento sobre procesos y fenómenos educativos.

Estas investigaciones se articularon con las dinámicas escolares de manera diversa, y en todos los casos tomaron la escuela como un escenario central para su desarrollo. Más allá del uso del espacio escolar, Ixs investigadorxs se vincularon a la cotidianidad de la escuela y establecieron relaciones con los actores escolares. En todos los casos hubo una participación importante de de Ixs maestrxs y/o una articulación con los espacios y las rutinas escolares, con propósitos explícitos, en el caso de algunos estudios, de enriquecer los proyectos educativos. Por ejemplo, Podestá Siri planteó la posibilidad de emplear los insumos de la investigación en la construcción de currículos interculturales. La investigadora realizó su exploración desde la escuela, de modo que Ixs niñxs traían a esta los conocimientos y las enseñanzas aprendidas en su pueblo y los expresaban a través de diferentes 
estrategias durante las clases. Del mismo modo, planteó los retos de "desarrollar un estudio de las representaciones sociales de pueblo que tienen niños nahuas en la escuela (institución cuya responsabilidad es transmitir e inculcar la cultura occidental y sus representaciones sociales)" (Podestá Siri, 2004, p. 54). Las estrategias utilizadas en este estudio difieren de las estrategias educativas empleadas por el grupo de docentes; por eso, la investigación ofrece metodologías e insumos para el desarrollo de currículos interculturales que involucren a maestrxs, abuelxs, padres y madres y otrxs actorxs, dado que "el reto es cómo ocupar el espacio ritual de la escuela para desarrollar, platicar, dibujar, hablar sobre cómo son sus mundos, qué es lo que ellos han aprendido de sus abuelos, de sus familias, en qué creen y en qué no creen, etc." (Podestá Siri, 2004, p. 136). Adicionalmente, se resaltan las posibilidades del espacio escolar para trabajar durante periodos prolongados de tiempo en diferentes temas con Ixs niñxs de manera individual y grupal fomentando la expresividad y la espontaneidad de los sus saberes.

Múltiples ideas y formas de trabajo se desprenden de este libro con el fin de contar con insumos para construir currículos interculturales. Cómo indiqué, los coautores de este trabajo son niños, pero los maestros podrían gestar propuestas entre maestros, sobre todo me refiero a los nativos $y$, ¿por qué no?, entre no nativos para confrontar ópticas. Aún más, esta metodología podría realizarse con abuelos o entre padres de familia; muchos actores pueden ejecutarla. Al revisarla, deberán efectuar un ejercicio de creatividad para formular sus propios proyectos de acuerdo con las realidades que enfrenten. (Podestá Siri, 2004, p. 17)

Por su parte, Guerrero Arias propone que los resultados del "viaje etnográfico" con los niñxs de la Escuela 11 de Octubre, de Catzuquí de Velasco puedan convertirse en material de estudio en esta y otras escuelas de la comunidad, de modo que Ixs niñxs puedan aprender de lo que sus abuelxs, madres y padres, familiares, vecinxs y amigxs les han compartido. El investigador trabajó conjuntamente con los maestros, de modo que los aprendizajes del proyecto se articularon con las asignaturas escolares, a las que se incorporó el conocimiento local, ausente en el currículo establecido.

Así, no se trataba de que aprendan geografía metidos en el aula frente a un mapa, como tradicionalmente se hace, sino haciendo caminatas de reconocimiento de sus lugares geográficos, sitios sagrados, sitios patrimoniales y turísticos, subiendo a sus cerros para que sientan su energía espiritual, etc. No se trataba de que aprendan sobre botánica y zoología con láminas en las aulas, sino que en el trabajo de campo puedan ir recolectando las plantas que sus abuelas y abuelos yachaks les hablaban 
que usan para la sanación de enfermedades; en lugar de un trabajo sobre historia que se ha reducido a memorizar fechas que nada tienen que ver con su cosmovivir, se trataba de que salgan tras las huellas de su propio pasado y presente y redescubran la historicidad de sus comunidades a través de lo que sus abuelas, abuelos y otras personas de la comunidad les trasmitan; y así se hizo con todas las materias, lo que resultó muy fructífero. (Guerrero Arias, 2017, p. 23)

De manera similar, el proyecto de Gandulfo se desarrolló en el marco de la propuesta educativa de la escuela. Las actividades de investigación se realizaron en el horario escolar, y aunque estas tenían un carácter diferente a las prácticas pedagógicas de la escuela, siempre se articularon con los contenidos que Ixs maestrxs enseñaban de acuerdo con el currículum oficial. Gandulfo afirma: "Sabemos que la institución de la escuela ha tenido como uno de sus objetivos centrales llevar adelante un proceso de homogeneización para facilitar la construcción de la 'nación'" (Gandulfo, 2007, pp. 30-31). Sin embargo, el trabajo conjunto con Ixs maestrxs y su vinculación en el equipo de investigación fue fundamental para abordar la cuestión de la lengua guaraní y sus usos en la escuela, de manera "que en el ámbito escolar se da un proceso posible de producción cultural -inversión (contra) hegemónica-, en el sentido de una creación y uso colectivo de materiales, significados, actos de habla, prácticas" (p. 67). Una maestra comenzó a usar el guaraní como lengua de enseñanza en el contexto del aula, y lxs niñxs fueron invitados a socializar los avances de su proyecto de caracterización lingüística durante una feria escolar, hasta que en un momento particular también se comenzó a usar el guaraní en los actos escolares. Así, las actividades del proyecto se fueron incorporando a la escuela $y$, en el segundo año de la investigación, la directora de la Escuela San Luis del Palmar solicitó a Ixs maestrxs incluir las actividades del proyecto en las planificaciones del año, de modo que "el proyecto de investigación terminó atravesando o atravesado por todas las áreas del currículum, transformándose en un proyecto institucional" (Gandulfo, 2016, p. 90).

Milstein también se incorporó al cotidiano escolar para identificar las prácticas políticas, las tensiones y las dinámicas sociales en la escuela N. ${ }^{\circ}$ 40, Islas Malvinas. La investigadora se vinculó participando en clases, reuniones, actos, almuerzos y también en actividades que tenían relación con la escuela, pero que se desarrollaban en otros lugares. También se interesó por los ámbitos de la vida comunitaria, en la medida en que le ayudaban a comprender las prácticas sociales y políticas que tenían lugar en la escuela. Un aspecto de esta investigación, distinto de los anteriores, es que al igual que con Ixs niñxs en estos espacios se incorporaron otros 
interlocutores poco visibilizados en las etnografías educativas, como las trabajadoras auxiliares de la escuela, las cocineras y las madres integrantes de la cooperadora; en este sentido, fue posible volver inteligibles aspectos del proceso de politización de la escuela que hubieran permanecido ocultos sin estas colaboraciones. En gran medida, fueron las perspectivas de Ixs niñxs las que condujeron a que la investigadora lograra ver fenómenos políticos en la escuela, que ni la literatura académica ni el sentido común dominante entre Ixs adultxs categoriza de ese modo. Entre estos, tal vez el más relevante para este análisis fue haber identificado que en la escuela también Ixs niñxs, en tanto estudiantes, son parte de los procesos de politización, y que esta participación está integrada e incorporada al aprendizaje escolar.

Los cuatro estudios fluyen con las dinámicas escolares establecidas. Observamos que las investigaciones no fueron pensadas en función de los currículos escolares, pero en el proceso, los enriquecen, los retan o los trascienden, promoviendo la producción de unos saberes que amplían el conocimiento escolar sobre su entorno. Las investigaciones generan una serie de actividades, intercambios, materiales y reflexiones que posicionan a la escuela como un espacio de producción cultural y de ejercicio político.

\section{Entretejiendo la colaboración}

La conformación de los equipos de investigación y las modalidades y estrategias colaborativas utilizadas con Ixs niñxs en estas cuatro etnografías exponen una variedad y multiplicidad ligada a los propósitos, los temas y problemas de investigación, los contextos empíricos seleccionados para realizar el trabajo de campo y las eventualidades o circunstancias impensadas, fortuitas, aprovechadas para enriquecer la marcha de las investigaciones. Como exponemos a continuación, la descripción de aspectos sobresalientes acerca de cómo en cada uno de los estudios se argumentaron y llevaron adelante las acciones y actividades colaborativas da cuenta de algunas singularidades respecto a la incorporación de NNJ a la investigación etnográfica.

El estudio realizado en México incluyó, entre sus propósitos iniciales, pensar un nuevo modelo metodológico para abordar las representaciones sociales infantiles desde una perspectiva antropológica y, en función de ello, abrirse a nuevas formas de acción conjunta entre investigador e investigado. Para llevar a cabo estas acciones, se propuso a niñxs cuyas familias eran nahuas y que asistían a escuelas de tres localidades — dos pueblos en áreas rurales y una ciudad - enviarse cartas entre sí. Esto permitiría estimular 
diálogos entre pares, de modo que emergieran interrogantes e inquietudes propios acerca de ellxs mismxs y de sus mundos. Tomemos en cuenta que el interés de la investigadora era entender con Ixs niñxs procesos diferenciados de construcción identitaria con relación a la cultura nahua y al lugar donde vivían. Para facilitar la expresión, la investigadora ofreció a las niñas y los niños opciones diversas de materiales y tecnologías: escritura en español y en náhuatl, oralidad, dibujos, fotografías y filmaciones. Con esta apertura la idea era que las cartas operaran como primer enlace, a través del cual pudieran conocerse entre sí y expresar algo de ellos mismos, de sus pueblos o de la ciudad. Este intercambio epistolar abrió un proceso interactivo entre pares, que fue construyendo autoría. Podestá Siri consideró indispensable lo que denominó "co-acción" y "co-construcción" entre los niños y la investigadora, para estudiar representaciones sociales en los contextos interculturales que propuso. A fin de organizar los textos de las cartas, ella hizo una propuesta amplia a varios grupos de las escuelas: "Cuéntame cómo es tu pueblo y cómo eres tú, para que yo te cuente cómo es el mío y cómo soy yo" (Podestá Siri, 2007a, p. 21). Este fue el punto de partida que originó una parte esencial del proceso compartido de acción y construcción, consistente en evocar. Otro conjunto de actividades compartidas fueron las entrevistas orales que realizaron Ixs niñxs a sus familiares o amigxs, y que variaron entre la lengua nahuátl y el español. Las conversaciones entre investigadorxs, niñxs y etnógrafa también jugaron un rol importante en el proceso de codirección de los análisis de las cartas y las entrevistas. La etapa de composición y edición de textos finales presentados como resultados de la investigación fue del mismo modo codirigida. Lxs niñxs de cada lugar organizaron manuscritos junto con la investigadora, utilizando el material documental de las cartas, las entrevistas y las conversaciones entre ellxs. Como comenta ella: "En sus múltiples expresiones [Ixs niñxs] van armando y discutiendo la representación social que tienen de su pueblo y en cada una de las actividades desarrolladas los tópicos centrales, los intereses, gustos y preferencias se reiteran" (Podestá Siri, 2007a, p. 51).

Estos manuscritos fueron mostrados a pobladorxs de cada localidad y a niñxs de otros lugares para que dieran sus impresiones sobre lo que leían.

Las opiniones, discrepancias, sugerencias y críticas (a veces fuertes) de los lectores foráneos se escribieron y enviaron a los autores, quienes las contemplaron en la nueva versión. Muchos de los reclamos se dieron entre los niños del campo y la ciudad, no entre pueblos. Porque los de la ciudad les muestran cosas que ellos ya conocen, y los del campo, como son hijos de migrantes, también conocen lo que hay en los pueblos. (Podestá Siri, 2007a, p. 52). 
También se trabajó de manera compartida para hacer las traducciones del náhuatl al español que se consideraron necesarias. Estos manuscritos, además de ser presentados en cada lugar, constituyeron el tercer capítulo del libro editado en coautoría por la etnógrafa y las niñas y los niños del campo y la ciudad. En este apartado del libro se presentaron las construcciones originales de Ixs niñxs que incluían fotografías, dibujos y descripciones en náhuatl y español. En la figura 1 se puede observar una fotografía con la explicación del niño-autor, junto con el texto que leyó antes de la publicación y que tenía la impresión de este sobre la imagen.

Figura 1

Material producido por Ixs niñxs

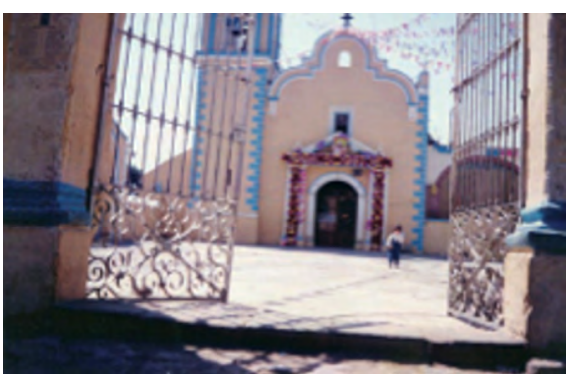

Esta fotografia tambien es otra parte de la iglesia esta por atras ahi se asen los papeles importantes de la iglesia como los de bautizos bodas invitaciones y defunciones esta es otra parte de la iglesia es la parte del patio aqui se hace la doctrina.

a mi me gusto la foto donde es una iglecia que dice perdona a tu pueblo tiene afuera adornos de flores rosas esta chiquita y me gustaria conocerla de adeveras lo qu eno me explico por que dice perdona a tu pueblo y tiene muchas cosas vonitas Sandra Marín Salgado, $5^{\circ}$ grado

Nota: Podestá Siri (2007a, p.103)

En Ecuador, la idea de organizar una investigación antropológica con grupos de niñxs de la escuela tuvo que ver directamente con una posición política del investigador, quien afirma que:

Trabajar con niñas y niños desde muy temprano en procesos de revitalización de la cultura, no tiene importancia solo teórica, académica o cultural, sino fundamentalmente política, pues hemos querido romper con esta visión "salvacionista", asistencialista colonial y colonizadora del "rescate" cultural, que transforma a las comunidades en meros objetos pasivos y reafirma su dependencia. (Guerrero Arias, 2017, p. 16)

El investigador invitó a Ixs estudiantes a realizar un trabajo antropológico, utilizando técnicas clásicas de la etnografía, fundamentalmente sobre sus vivencias. El proceso se desarrolló durante un viaje que realizó con ellxs y con dos maestros. Mediante distintas estrategias que incluyeron caminar 
y recorrer, jugar, conversar con pobladores, escribir, leer, cantar, dibujar y pintar, fueron en busca de:

[...] los significantes, los significados y las significaciones que están en los imaginarios y representaciones con las que las y los comuneros de Catzuquí de Velasco sienten y piensan el mundo y su existencia, para que escuchen su palabra, sus discursos a través de los cuales hablan sobre sus experiencias vitales, y puedan experimentar y participar de lo que hacen, de sus praxis sociales. (Guerrero Arias, 2017, p. 18)

Figura 2

Taller: jugando a las investigadoras y a los investigadores

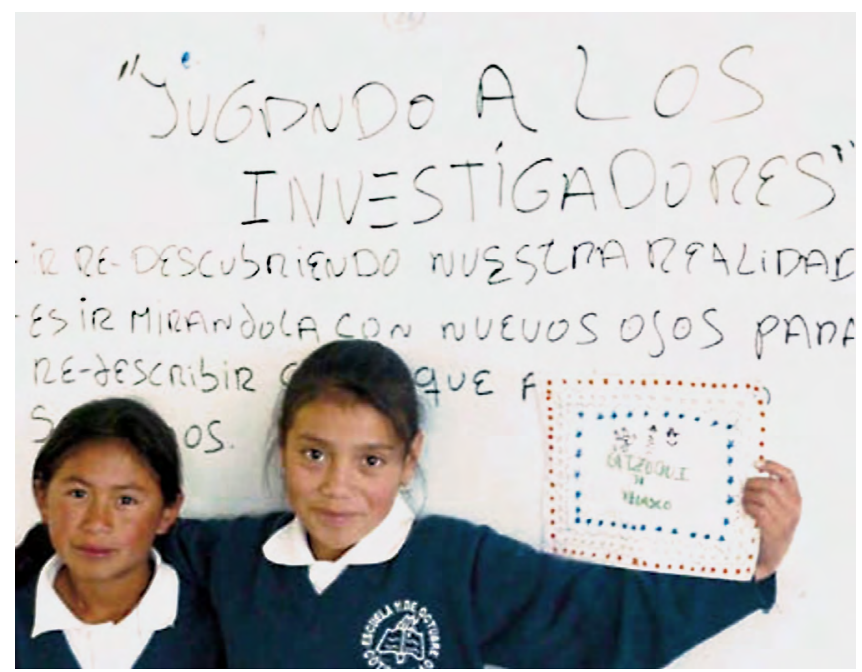

Nota: Guerrero Arias (2017, p. 24)

El investigador preparó una primera etapa del viaje, realizando talleres de intercambio que le permitieran conocer lo que pensaban y sentían Ixs niñxs al escuchar la propuesta. Uno de los talleres estuvo dedicado a conversar acerca de qué era investigar.

Otro taller inicial se enfocó en conversar sobre la noción de corazonar, para compartir con las niñas y los niños que sentir y pensar son dos acciones que van juntas, y que se trata de una noción tomada de las sabidurías ancestrales de los pueblos de Abya-Yala:

'Somos estrellas con corazón y con conciencia', que nos constituye la unidad indisoluble entre la afectividad y la reflexión, que somos un pequeño Bioverso, un micro-cosmos caminante que siente, piensa, ríe, llora, ama, sueña; de ahí que el corazonar no niega la razón, sino que da ternura a la inteligencia. (Guerrero Arias, 2017, p. 33) 
Nos interesa destacar que en estos talleres iniciales el investigador compartió con Ixs niñxs discusiones en torno a los usos de las palabras, las categorías y las formas de nombrar, apoyándose en los saberes ancestrales de la cultura que quería redescubrir junto a ellxs. Por eso lxs involucró desde el inicio en un aspecto poco frecuente en el trabajo colaborativo, como es la explicitación de decisiones epistemológicas y posiciones éticas y políticas de las y los investigadores en la realización de sus estudios. Así por ejemplo, instó a romper con lo hegemónico patriarcal, nombrando primero lo femenino y luego lo masculino, además de cambiar el concepto de universo y suplantarlo por pluriverso; por último, trabajó la diferencia entre folclor y cultura, entre otros aspectos.

Los talleres que acompañaron todo el proceso de trabajo de campo y de escritura fueron concebidos como espacios para crear y recrear relatos, mitos, historias, leyendas, canciones, dibujos e ilustraciones. De esta manera, fueron produciendo datos alrededor de tres ejes (espacialidad, temporalidad y sentido) que el investigador estableció desde el inicio, y que fueron reelaborados con Ixs niñxs a partir de la experiencia realizada para el último capítulo del libro de autoría colectiva, coordinado por el investigador. Durante el trabajo de campo las niñas y los niños tomaban notas en sus diarios de campo y registraban sus recorridos, lo que veían, lo que les contaban, lo que hacían. Por grupos compartían la información, la procesaban y producían datos con una multiplicidad de formas expresivas que iban desde el texto escrito, el dibujo, el mapa, la maqueta, hasta la elaboración de tablas y calendarios. En las figuras 3, 4 y 5 se observan sus registros sobre diferentes aspectos del territorio.

Figura 3

Nuestra comida

\begin{tabular}{|l|l|}
\hline Platos & Con qué nomas le preparamos \\
\hline Catzos blancos & $\begin{array}{l}\text { Catzos blancos/café claros, ajo machacado, } \\
\text { comino, sal aceite o manteca de chancho }\end{array}$ \\
\hline Colada de cebada & Cebada, col, papas, ajo, cebolla, agua, carne de puerco \\
\hline Sopa de trigo & Harina de trigo, cebolla, papas, sal, agua \\
\hline Sopa de fideo & Leche/agua, fideo, queso, cebolla, papás, \\
\hline Mondongo & Tripa de borrego, papás, leche/agua \\
\hline Papas con cuero & Papás, cuero de chancho, maní, cebolla, sal, ajo, leche/agua \\
\hline Arroz con huevo & Arroz, huevo \\
\hline Caldo de 31 & Tripage de vaca, sal, ajo, agua \\
\hline Caldo de gallina & Gallina de campo, papás, ajo, apio, cebolla, agua \\
\hline Locro de papas & Papás, leche, queso, zanahoria, sal, ajo, agua \\
\hline Salchipapas & Salchichas, papás \\
\hline
\end{tabular}


Figura 4

Reconstruyendo la memoria desde la comunidad

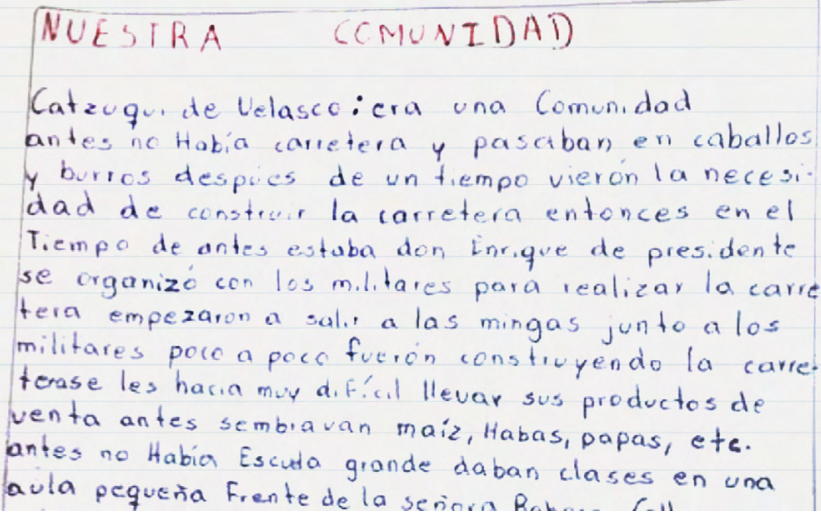

Nota: Guerrero Arias (2017, p. 77)
Figura 5

Trabajo identificando mi comunidad

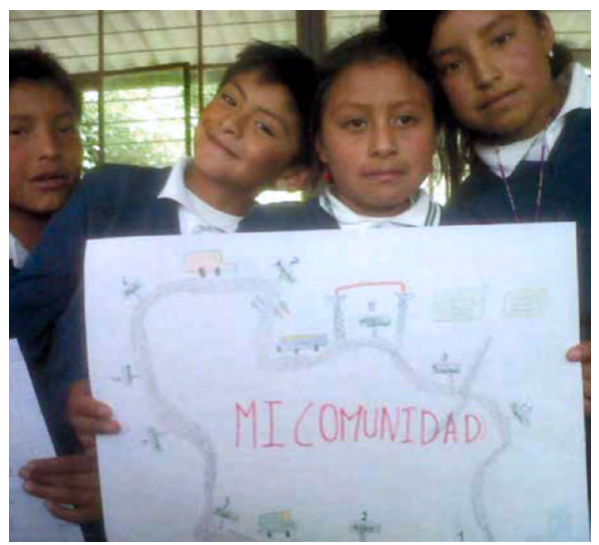

Nota: Guerrero Arias (2017, p. 78)

En este estudio, a diferencia del realizado en México, las fotografías fueron tomadas por maestros que oficiaron como equipo de acompañamiento. Las imágenes narran una parte importante sobre su experiencia con el libro e incluyen sus perspectivas de acompañamiento del proceso. El desafío de Guerrero Arias es superar el texto monofónico para exponer los resultados en una polifonía, donde se entrelazan las voces y perspectivas de adultxs, y niñxs de la comunidad y la del mismo investigador. En todos los capítulos resuenan los modos de hacer, sentir pensar, hablar, cantar, dibujar, fotografiar y escribir de todas y todos los participantes: niñas, niños, adultos interlocutores, maestros, fotógrafos y etnógrafos.

Los otros dos estudios, de Gandulfo y Milstein, no plantearon en el proyecto inicial la colaboración de niñas y niños, sino que esta fue la consecuencia de sucesos ocurridos durante el trabajo de campo. En uno de ellos, la investigadora no tenía previsto que tres niñas pudieran elaborar de forma rápida y artesanal un censo lingüístico en la escuela. Tampoco sabía que los datos producidos por ellas iluminarían de manera original los problemas de su investigación. Sorprendentemente, Carolina Gandulfo, basándose en los datos del censo realizado por las estudiantes, advirtió que Ixs niñxs hablantes de guaraní de los dos primeros grados constituían un $75 \%$. Con esta información se dio cuenta que en la escuela Ixs niñxs en proceso de alfabetización (en español) eran mayoría, y que el concepto de minoría lingüística operaba, en esa situación, como "una estrategia de dominación a partir de ideologías lingüísticas construidas sobre la base de comparaciones —que minorizan o mayorizan - entre grupos que usan distintas lenguas" (Gandulfo, 2007, p. 169). A través de planillas como las que mostramos a 
continuación (figura 6), las niñas mostraron una síntesis de su relevamiento respecto al uso de las lenguas y sus hablantes.

Figura 6

Planilla A2 IPlanilla síntesis
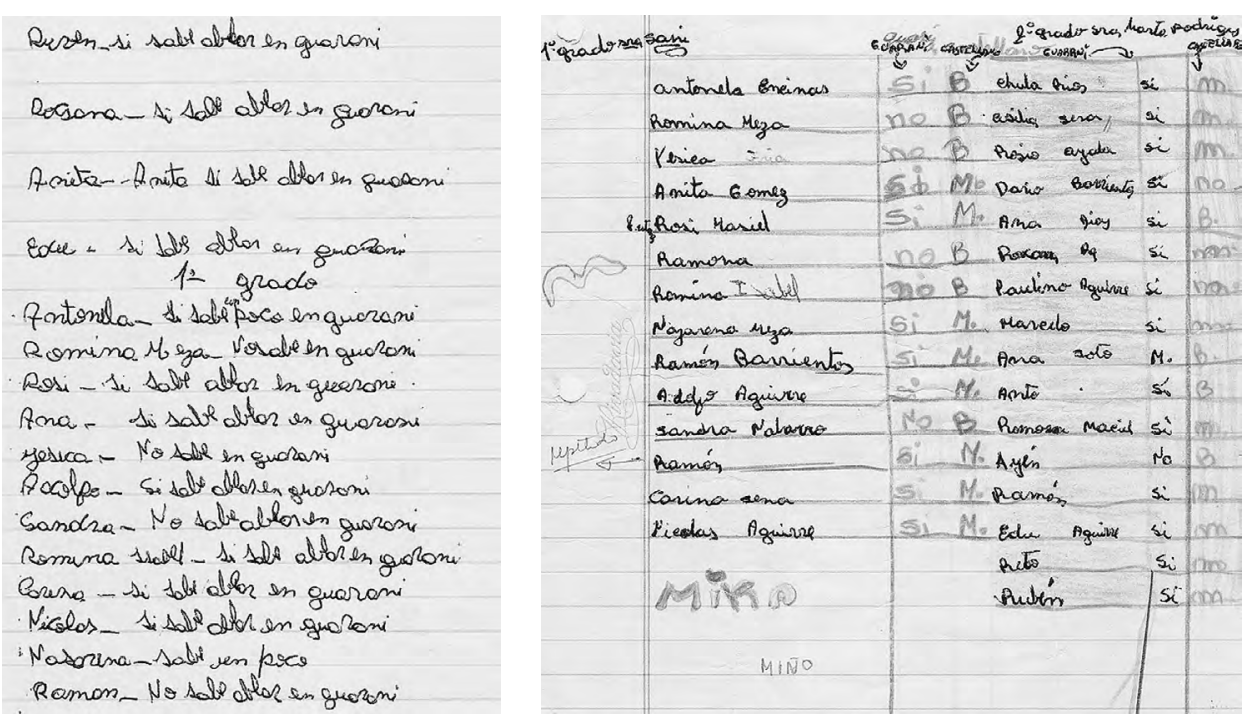

Nota: Gandulfo (2007, p. 52 y 55)

Con la ayuda de la investigadora se pudo organizar una tabla de doble entrada con las cantidades y los porcentajes de niñxs hablantes de una y otra lengua, en los dos primeros grados de escolaridad.

Tabla 1

Cantidad de niños que hablan una u otra lengua

\begin{tabular}{|c|c|c|c|c|c|}
\hline \multirow{2}{*}{$\begin{array}{c}\begin{array}{c}\text { Lengua y } \\
\text { competencia }\end{array} \\
\text { Guaraní sí }\end{array}$} & \multicolumn{2}{|c|}{$\begin{array}{c}1^{\text {er }} \text { año } \\
13 \text { alumnos }\end{array}$} & \multicolumn{2}{|c|}{$\begin{array}{c}2^{\text {do }} \text { año } \\
15 \text { alumnos }\end{array}$} & \multirow{2}{*}{$\begin{array}{c}\text { Porcentaje sobre el total } \\
\text { de niños } \mathbf{1}^{\text {er }} \mathbf{y}^{\text {do }} \text { año } \\
75 \%\end{array}$} \\
\hline & 8 & $61.53 \%$ & 13 & $86.66 \%$ & \\
\hline Guaraní no & 5 & $38.47 \%$ & 2 & $13.33 \%$ & $25 \%$ \\
\hline Castellano bien & 6 & $46.15 \%$ & 4 & $26.66 \%$ & $35.71 \%$ \\
\hline $\begin{array}{l}\text { Castellano } \\
\text { más o menos }\end{array}$ & 7 & $53.85 \%$ & 10 & $66.66 \%$ & $60.71 \%$ \\
\hline Castellano no & - & - & 1 & $6.66 \%$ & $3.57 \%$ \\
\hline
\end{tabular}

Nota: Gandulfo (2007, p.56)

El aporte de las niñas respecto a un tema complejo como el de los usos lingüísticos no solo fue la estrategia censal, sino algo aun más relevante: una expresión conceptual para nombrar un tipo de bilingüismo complejo 
específico. En palabras de la autora, "estos niños no pueden ser catalogados como monolingües en castellano, pero tampoco como bilingües coordinados, y no todos como monolingües en guaraní [... ] sino como bilingües compuestos: 'guaraní sí, castellano más o menos'" (Gandulfo, 2007, p. 174).

En el otro estudio realizado en Argentina, lo inesperado para la investigadora fue que en la interlocución con Ixs niñxs se hicieran visibles fenómenos de índole política en el espacio social de la clase y que estos fueran protagonizados por estudiantes y docentes. Ella no imaginaba cuánto entendían Ixs niñxs acerca de las relaciones entre la política, la escuela y el barrio, pero al advertir la relevancia que tenían sus modos de ver y entender, decidió realizar una parte del trabajo de campo con ellxs. En palabras de la investigadora:

Mi preocupación, concentrada en mirar las prácticas escolares en su dimensión política, me orientaba — hoy diría de manera reduccionistahacia aquello que hacían y decían los adultos. Me costaba advertir que en varias oportunidades, y a veces sin que me diera cuenta del todo en el momento, niños y niñas hacían comentarios, contaban situaciones y mostraban conocimientos relativos al tema que me interesaba [...].Advertí que lo más interesante que ellos me aportaban no eran informaciones o datos puntuales, sino su modo de transmitirlas, las asociaciones que hacían, lo que señalaban como relevante, sus comentarios y observaciones. A través de sus relatos, las vidas familiares y la vida escolar ingresaban a un relato claro, diáfano y muy vivaz. De este modo, yo lograba entender, desde una perspectiva distinta, algunas situaciones y ciertos modos de relación, así como llenar espacios vacíos en los relatos de los adultos. (Milstein, 2009, p. 44)

El trabajo de campo en esta etnografía fue sostenido durante los años 2004 y 2005 y, aproximadamente durante tres meses en cada uno de estos años, se incorporó la colaboración de niñxs (entre once y catorce años de edad), con el propósito de conocer y registrar versiones acerca de la vida en la localidad y la escuela, incluyendo la percepción que tenían del mundo social, lo que permitió a la investigadora comprender los lugares de maneras inéditas. Como ella cuenta, en una ocasión Ixs niñxs le propusieron visitar un lugar que era "como una plaza", pero "no era una plaza porque no tenía juegos ni nada", según le explicó un alumno. Lxs niñxs le mostraron la representación de ese lugar en el mapa que habían elaborado y ella vio allí dibujados dos árboles y una flor, pero cuando llegó no vio ni árboles ni flores. 
Mi sorpresa fue cuando llegamos. Yo no veía un lugar de juego con árboles y flores tal como estaba dibujado por ellxs en el papel. Vi un baldío abierto, sin muro ni puerta que lo separara de la acera $y$, desde mi punto de vista, no era una plaza sino a un "yuyal", en el mejor de los casos. No tuve tiempo para pensar mucho en esto porque Ixs niñxs vieron que no estaba entre ellxs y una dijo: "Diana, ivení!, imirá!". Me acerqué caminando lento entre las plantas que llegaban a la altura de mis rodillas. Había cajas vacías, papeles, alguna que otra lata y botellas de plástico. Uno de los chicos tenía un palo en la mano con el que interceptaba el camino de hormigas y se reía mucho. Atrás del predio había una parte de tierra, sin plantas, donde me contaron que hacían "partiditos" — practicaban fútbol entre ellos. Estuvimos unos 15 o 20 minutos allí yendo de una punta a la otra del terreno, haciendo carreras entre las plantas, buscando insectos, jugando con una pelota, entre otras actividades. (Clemente \& Milstein, 2019 , p. 10)

Haciendo lo que hacían Ixs niñxs allí, la investigadora logró ver y escuchar lo que no le hubiera sido posible distinguir sin ellxs. Unos días después en la escuela le contó a una maestra dónde habían ido y la maestra identificó ese terreno como baldío. La investigadora logró así entender la importancia que tenía el trabajo de campo colaborativo con estxs niñxs para captar los usos y sentidos de categorías claves como plaza, yuyal y baldío, y para comprender la localidad, las relaciones entre sus pobladorxs y los lugares e, inclusive, el impacto educativo que estos usos y sentidos podían tener.

Durante los recorridos por las calles y las plazas y las visitas a casas de familiares, edificios locales destinados a atención de salud, bomberos voluntarios, y el centro comercial, entre otros, mientras caminaban, corrían y jugaban, observaban, comentaban, conversaban entre ellxs y con otrxs, intervenían en alguna actividad que estaba ocurriendo y en algunas oportunidades también, se hicieron entrevistas. Lxs niñxs sobre todo, registraban grabando y fotografiando. La investigadora escribía sus propias notas, y aunque ellxs pocas veces lo hacían, compartían las notas de ella, escribiendo algo, pidiéndole que registrara algo en particular o simplemente leyendo y comentando el texto. Es así como, en esta investigación, las notas de la etnógrafa "tomaron la forma de un texto escrito colaborativo" (Milstein et al., 2019, p. 145). En distintas oportunidades el cuaderno de notas de la investigadora era solicitado por Ixs niñxs para recordar lo realizado en los recorridos y, a veces, era leído en las reuniones que ella mantenía con el equipo de niñxs en la escuela, fuera del horario de clases. En estas reuniones intercambiaban ideas sobre las actividades que se desarrollaban con el 
grupo, dibujaban mapas y croquis del lugar (pocas veces dibujaba la investigadora), escuchaban partes de las grabaciones, miraban las fotografías cuando estaban reveladas y copiadas en papel, organizaban y planeaban los recorridos y las visitas, definían preguntas para hacer durante los encuentros, leían las trascripciones de las grabaciones que les llevaba impresas la investigadora y, durante el último mes, en ambos grupos se dedicaron las reuniones a organizar y componer los textos que publicarían colectivamente. Estas publicaciones son libros editados de manera artesanal, con pie de imprenta de la escuela, y fueron presentados en noviembre de 2004 y diciembre de 2005, respectivamente. Los textos ofrecen versiones inteligibles de la vida social local, reuniendo de manera polifónica un conjunto de historias y comentarios de adultxs, jóvenes y niñxs, de edades, procedencias, familias y ocupaciones diversas. Aquí se narran y describen los recorridos, caminatas y conversaciones que en distintos momentos y situaciones mantuvieron Ixs niñxs y la investigadora, y también incluyen diálogos con vecinxs adultxs y niñxs, familiares, docentes, estudiantes y auxiliares de la escuela incluyendo textos escritos, transcripciones de textos orales, mapas dibujados por Ixs niñxs e imágenes fotografiadas.

Figura 7

Tapa del primer libro, 2004. Tapa y contratapa del segundo libro, 2005
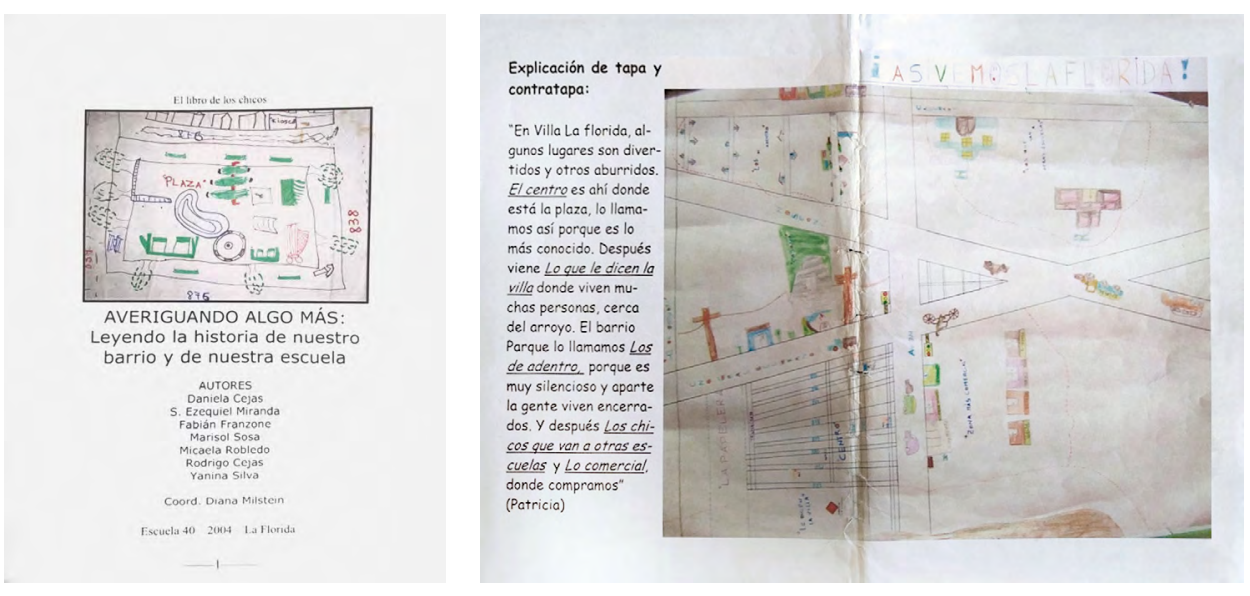

Nota: Milstein et al. (2004); Milstein et al. (2005)

Como hemos mostrado, los cuatro estudios exhiben entre sus resultados tangibles los alcances que tuvo el reconocimiento de Ixs niñxs como actores sociales competentes e involucrarlos activa y protagónicamente en los procesos de indagación sobre sus mundos culturales y políticos, y a las escuelas como centros de encuentro, reunión, trabajo y actividad. 


\section{Conclusiones}

Los estudios que hemos analizado en este artículo nos muestran las posibilidades que ofrece la etnografía colaborativa con niñxs como enfoque para la producción y expansión del conocimiento en el campo educativo, así como para el enriquecimiento del conocimiento escolar sobre la escuela. Las cuatro investigaciones presentan a la escuela como un lugar de producción de conocimiento sobre los contextos locales y muestran cómo el proceso de estudio compartido con niñxs posibilita que esta sea experimentada como un escenario de actuación política. También evidencian que NNJ ponen en escena y en discusión, de maneras originales y no previstas por Ixs investigadores, temas altamente relevantes para el campo de la educación, tales como los usos o no usos legítimos de las lenguas, la relación entre el trabajo y la política en los barrios y los sentidos de la memoria colectiva y el patrimonio.

Este análisis también presenta cómo la colaboración entre niñxs y adultxs pone en entredicho los roles asignados a los primeros como aprendices en proceso de socialización, y a adultxs como enseñantes ya socializados, y evidencia la necesidad de pensar antropológicamente los procesos de aprendizaje. Así, cuestiona el rol aparentemente inmutable de los expertos. Podestá Siri propone una dinámica de comunicación niñx-niñx en la que ellos despliegan sus tópicos de interés y organizan sus discursos desde sus propias lógicas culturales, "es increíble ver a los niños tomar fuerza para hablar de ellos y de su pueblo, nada parece detenerlos" (Podestá Siri, 2007b, p. 998). La experiencia de Catuzuqí muestra su experticia como aprendices principales, pero sobre todo como revitalizadores de saberes sobre el territorio. Gandulfo y Milstein confirman que Ixs niñxs se configuran como expertos nativxs y como poseedorxs de conocimientos sobre sus contextos, señalando lo que las investigadoras no alcanzan a vislumbrar a simple vista.

Destacamos, a través de ejemplos que tomamos de los cuatro estudios, aspectos puntuales que resultan innovadores para la investigación educativa. Uno de ellos se relaciona con la manera como se práctica la etnografía en equipos constituidos por una cantidad numerosa de investigadorxs. Otro está referido a los retos que plantea desarrollar investigación social en el espacio escolar y, particularmente, en el salón de clases, a fin de que Ixs estudiantes adquieran, en términos de conocimiento, autoridad frente a Ixs adultxs docentes e investigadores. Un tercer aspecto se relaciona con la relevancia que tienen los lenguajes no verbales en el trabajo de campo; esto no debe entenderse como un efecto "lógico" por tratarse de niñxs, sino como una forma innovadora de enriquecer las estrategias de observación participante, de intercambio con los actores locales, de 
reconocimiento del espacio, de construcción de datos, permitiendo expresar representaciones a partir de las lógicas propias, los saberes y los órdenes culturales. El cuarto punto alude a cómo poner en discusión perspectivas dominantes en la investigación educativa, que tienden a excluir y/o subsumir el protagonismo de la mayoría de los actores, minimizando así el conocimiento local imprescindible para desarrollar nuevas y originales comprensiones de procesos educativos y para el aporte del trabajo de campo y de la escritura compartida entre etnógrafos y niñxs.

Los estudios se adentran en el mundo de Ixs niñxs a través de las acciones emprendidas por estos como sujetos protagónicos. Con respecto a los estudios sociales de infancias y juventudes, la etnografía colaborativa con NNJ genera condiciones para poner en debate, desde las experiencias propias, concepciones analíticas generadas por la psicología del desarrollo infantil y del conductismo. Como efecto de ello, también se identifican algunos modos que proponen autonomía para pensar, percibir e interpretar, pero que en últimas estimulan mecanismos de control, disciplinamiento e incluso, sometimiento.

Finalmente, las modalidades colaborativas que incluyen a NNJ como etnógrafxs potencian la investigación antropológica, en tanto amplían las posibilidades de organizar experiencias e intercambiarlas en relaciones de diálogo horizontal entre académicxs y no académicxs, dando lugar a que el conocimiento local fluya, minimizando y reduciendo los efectos negativos y distorsionantes de las relaciones de autoridad y poder sobre la producción de conocimiento. Estas cuatro investigaciones lograron, de maneras distintas y creativas, asumir el reto de dar un espacio autónomo a la autoría infantil en el texto científico. De manera similar, también son una invitación para que los docentes incluyan a sus estudiantes como coproductores de los proyectos educativos y como coautores de las experiencias de docencia, para facilitar la incorporación plena de las perspectivas de quienes constituyen el grupo mayoritario de actores escolares.

\section{Sobre los autores}

Diana Milstein es investigadora del Centro de Investigaciones Sociales de doble dependencia CONICET y del Instituto de Desarrollo Económico y Social (CIS-CONICET/IDES), Buenos Aires, Argentina. Coordinadora general de la Red Internacional de Etnografía con Niñas, Niños y Jóvenes (RIENN). Sus investigaciones se han orientado hacia temáticas que abarcan la construcción social de los cuerpos, la infancia, la política y la vida cotidiana en las escuelas, la educación artística y la estética escolar, la salud y la educación médica y el enfoque etnográfico en colaboración con niños y niñas. 
Alba Lucy Guerrero es profesora de la Facultad de Educación de la Pontificia Universidad Javeriana, Bogotá, Colombia. Líder de la línea de investigación Infancias, Cultura y Educación. Co-fundadora de la Red Internacional de Etnografía con Niños y Niñas (RIENN). Sus intereses de investigación se centran en la antropología de la infancia y métodos de investigación colaborativa, incluyendo etnografía y narrativas.

\section{Referencias}

Barabtarco A., Zedansky, Y., \& Poaschner, M. T. (1998). Participatory Action Research in Teachers education method for studying the everyday reality of teaching in Latin America. En G. Anderson \& M. Montero-Sieburth (Eds.), Educational Qualitative Research in Latin America. The Struggle for a New Paradigm (pp. 161-180). Garland Publishing.

Batallán, G. (1998). Appropriating Ethnography for Research in Education. Reflections on Recent Efforts in Argentina and Chile. En G. Anderson \& M. Montero-Sieburth (Eds.), Educational Qualitative Research in Latin America. The Struggle for a New Paradigm (pp. 35-50). Garland Publishing.

Bertely, M., \& Corenstein M. (1998). An Overview of ethnographic Research in Mexico. En G. Anderson \& M. Montero-Sieburth (Eds.), Educational Qualitative Research in Latin America. The Struggle for a New Paradigm (pp. 51-76). Garland Publishing.

Clemente, A y Milstein, D. (2019). Abriendo ventanas para ver y entender. Etnografía en colaboración con niñas, niños y jóvenes. Papeles de Trabajo sobre Cultura, Educación y Desarrollo Humano, 15(2), 1.

Convención sobre los Derechos del Niño (1989). Unicef Colombia. X Aniversario de la Convención sobre los Derechos del Niño.

De Certau, M. (2007). La invención de lo cotidiano. Universidad Iberoamericana.

Fals-Borda, O. (1978). El problema de cómo investigar la realidad para transformarla por la praxis. Tercer Mundo Editores.

Fabian, J. (2007). Memory against Culture: Arguments and reminders. Duke University Press.

Gajardo, G. (1985). Investigación Participativa en América Latina. [Documento de trabajo n. ${ }^{\circ}$ 261]. Programa FLACSO.

Gandulfo, C. (2007). Entiendo, pero no hablo. El guaraní "acorrentinado" en una escuela rural. Antropofagia.

Gandulfo, C. (2016). "Hablan poco guaraní, saben mucho". Una investigación en colaboración con niños y maestros en un contexto bilingüe de Corrientes, Argentina. Signo y Seña, (29), 79-102.

Guerrero, A.L., Clemente, A., Dantas-Whitney, M., \& Milstein, D. (2017). Bordes, límites y fronteras. Etnografía en colaboración con niños, niñas, adolescentes y jóvenes. Editorial Pontificia Universidad Javeriana.

Guerrero Arias, P. (Coord.) (2017). Catzuquí de Velasco. Cultura, identidad y memorias vivas. Etnografiando con niñas y niños. Abya-Yala y UPS.

Jaramillo, J., \& Fernández, S. (Eds.) (2018). Panorama sobre etnografía con niñas, niños, adolescentes y jóvenes. En Argentina, Brasil, Colombia y Ecuador. 1995-2006. RIENN. 
Ingold, T. (2017). iSuficiente con la etnografía! Revista Colombiana de Antropología, 53(2), 143-159. https://doi.org/10.22380/2539472X.120

Levinson, B., Sandoval-Flores, E. M., \& Bertely-Busquets, M. (2007). Etnografía de la Educación, Tendencias Actuales. Revista Mexicana de Investigación Educativa, 12(34), 951-986.

Milstein, D. (2009). La nación en la escuela. Viejas y nuevas tensiones políticas. Miño y Davila y CAS/IDES.

Milstein, D. (2010). Politics is also "child's play". Teaching and Teacher Education 26(1), 136-143. https://doi.org/10.1016/j.tate.2009.08.002

Milstien, D. (2020) Niñas, niños, jóvenes y la etnografía: educación y descentramientos. Diálogos sobre educación, 11(20), 1-10. https://doi.org/10.32870/ dse.v0i20.690

Milstein, D., Cejas, D., Miranda, E., Franzone, F., Sosa, M., Robledo, M., Cejas, R., \& Silva, Y. (2004). Averiguando algo más: Leyendo la historia de nuestro barrio y de nuestra escuela. Escuela 40, La Florida. Texto inédito.

Milstein, D., Clemente, A., Dantas-Whitney, M., Guerrero, A. L., \& Higgins, M. (2011). Entre espacios y tiempos compartidos: Encuentros etnográficos con niñ@sy adolescentes. Editorial Miño Dávila.

Milstein, D., Clemente, A., \& Guerrero, A. L. (2019). Collaboration in educational ethnography in Latin America. Oxford Research Encyclopedia of Education. Oxford University Press. doi: http://dx.doi.org/10.1093/acrefore/9780190264093.013.565

Milstein, D., \& Mendes, H. (2017). La escuela en el cuerpo. Estudios sobre el orden escolar y la construcción social de los alumnos en escuelas primarias. Miño y Dávila y CAS/IDES.

Milstein, D., Mieres, C., Cejas, D., Mieres, L., Lugo, P., Cejas, R., \& Silva, Y. (2005). iVemos La Florida! Texto inédito.

Pavez Soto, I. (2012). Sociología de la infancia: las niñas y los niños como actores sociales. Revista de Sociología, (27), 81-102.

Podestá Siri, R. (2004). Otras formas de conocernos en un mundo intercultural. Experiencias infantiles innovadoras. Revista Mexicana de Investigación Educativa, 9 (20), 129-150.

Podestá Siri, R. (2007a). Encuentro de miradas: El territorio visto por diversos autores. Secretaría de Educación Pública.

Podestá Siri, R. (2007b). Nuevos retos y roles intelectuales en metodologías participativas. Revista Mexicana de Investigación Educativa, 12(34), 987-1014.

Reygadas, L. (2014). Todos somos etnógrafos. Igualdad y poder en la construcción del conocimiento antropológico. En C. Oehmichen Bazán (Ed.) La Etnografía y el trabajo de campo en las ciencias sociales (pp. 91-118). Universidad Autónoma de México.

Rockwell, E. (1998). Ethnography and the commitment to Public Schooling. A review of Research at the DIE. En G. Anderson, \& M. Montero-Sieburth (Eds.) Educational Qualitative Research in Latin America, The Struggle for a New Paradigm (pp. 3-34). Garland Publishing. 
Torres, A., \& Cendales, L. (2006). La sistematización como experiencia investigativa y formativa. La Piragua, (23). http://www.cepalforja.org/sistem/ documentos/lola_cendales-alfonso_torres-la_sistematizacion_como_ experiencia_investigativa_y_formativa.pdf

Vergara, A., Peña, M., Chávez, P. y Vergara, E. (2015). Los niños como sujetos sociales: El aporte de los Nuevos Estudios Sociales de la infancia y el Análisis Crítico del Discurso. Psicoperspectivas, 14(1),55-65. http://dx.doi.org/ 10.5027/psicoperspectivas-Vol14-Issue1-fulltext-544 